\title{
A CERIMÔNIA DO CHÁ COMO FATOR DE IDENTIDADE CULTURAL PARA IMIGRANTES JAPONESES E SEUS DESCENDENTES \\ NO BRASIL'
}

RESUMO: Utilizando o interesse em estudar a cerimônia do chá, uma arte tradicional japonesa, como fio condutor, a autora examina as atitudes e o posicionamento dos imigrantes frente à assimilação cultural. Para isto, é traçado um paralelo entre o momento histórico brasileiro a partir da década de 50 e o comportamento dos imigrantes e seus descendentes. Issei e nissei seguiram direções diversas após a Segunda Guerra Mundial. Com uma situação econômica mais estável, e sem possibilidade de volta ao Japão que havia perdido a guerra, os issei procuraram voltar às raízes e aos valores japoneses. Por outro lado, os nissei precisavam aculturar-se para ascender socialmente e, portanto, procuraram distanciar-se dos valores tradicionais da cultura japonesa para aprender a ser brasileiros. Entretanto, a partir da década de 80 o Japão detém um papel central no cenário mundial. Há uma revalorização da tradição japonesa e não só os nissei e sansei tomam interesse por ela, mas também brasileiros não-descendentes.

ABSTRACT: This article makes use of a traditional Japanese art, tea ceremony, to examine the attitudes of immigrants who have to face cultural assimilation. In order to

1. O presente artigo baseia-se no segundo capítulo da dissertação de mestrado defendida em dezembro de 1996 na Escola de Comunicação e Artes da USP, com o título A Cerimônia do Chá no Japão e sua Reapropriação no Brasil: uma Metáfora da Identidade Cultural do Japonês. Neste capítulo investigo a história da cerimônia do chá, ou chanoyu, no Brasil e o significado que teve e tem para os diversos grupos que aqui a praticam.

2. A autora é doutoranda no Depto. de Antropologia/USP, Mestre pela ECA/USP e Bacharel em Ciências Sociais pela FFLCH/USP. Foi bolsista da Fundação Urasenke e ganhadora do primeiro lugar na área de Cultura do Concurso Nacional de Monografias, evento comemorativo do Centenário do Tratado de Amizade e Navegação Japão-Brasil. Endereço para correspondência: Al. Jaú, 555, apto. 72 01420-000 - São Paulo - SP - Tel.: (011) 2893909 - E-mail: cmrocha@uol.com.br 
do that the author draws a parallel between Brazilian history after World War II and the behavior of immigrants and their descendants since then. Issei (first generation) and nissei (second generation) led different ways since the end of the war. Enjoying a more economically stable situation, and having nowhere to go back to (since Japan had lost the war), the isse $i$ went back to their roots and started learning tea ceremony. On the other hand, the nisse i needed to assimilate the Brazilian culture if they were to ascend economically and socially. However, since the 80 's Japan has played a central role in the world's economy and politics. Therefore, there is a new interest in its traditional culture. The research revealed that, presently, not only are nissei and sansei (third generation) willing to learn tea ceremony, but also Brazilians who are non-Japanese descendants.

PALAVRAS-CHAVE: Cerimônia do chá, reapropriação, identidade étnica, imigrantes, assimilação cultural, fricção interétnica

KEYWORDS: Tea ceremony, appropriation, ethnic identity, immigrants, cultural assimilation, intherethnic friction

Funcionando como um sistema ético e de conduta, a cerimônia do chá, ou chanoyu, oferece um campo privilegiado para uma investigação do que foi escolhido e o que foi transformado pelos imigrantes e seus descendentes no Brasil como representativo de seu ethos japonês. Através destas escolhas pode-se perceber o que selecionaram para lembrar-se de suas origens e quais elementos da cultura brasileira foram incorporados.

A desorganização e reorganização sociais que os imigrantes e seus descendentes tiveram que enfrentar ao viver entre duas ordens de valores fez com que este sistema ético fosse adotado de maneiras diferentes por uns e outros.

Atualmente mais dois grupos juntaram-se a estes que primeiro praticaram o chanoyu: os japoneses não-imigrantes e brasileiros não-descendentes. E o Japão não poderia viver uma realidade mais distinta daquela de 1954, quando o chanoyu chegou ao Brasil. Como uma das maiores potências econômicas mundiais, o país faz nascer um interesse mais intenso por sua cultura. Brasileiros não-descendentes de japoneses encontram nesta arte uma porta estreita, mas de acesso possível para a compreensão da cultura japonesa. Com companhias japonesas espalhadas pelo globo, executivos japoneses vêm à São Paulo trabalhar temporariamente e suas esposas tornam-se igualmente parte do corpo de alunos.

Dados estes grupos tão variados, é relevante analisar com o que contribui cada um deles para a maneira como o chanoyu é feito e estudado no Brasil e o que esperam conseguir com seu estudo. Todavia, são os conflitos entre eles que nos falam de suas aspirações. A questão da identidade e as lutas de poder são peças fundamentais na existência do chanoyu entre nós.

Veremos adiante como se deu o processo de chegada do chanoyu no Brasil, seu desenvolvimento e o que significou para a população que se interessou em aprendê-lo. 


\section{A Chegada do Chanoyu no Brasil}

O ano de 1954 foi decisivo para que a colônia japonesa de São Paulo voltasse a estabelecer sua identidade depois da guerra e para a afirmação da cidade como um centro cosmopolita. Veremos a seguir como ocorreu este processo.

No momento em que a derrota do Japão se tornou fato inelutável, os antigos imigrantes tiveram que enfrentar a dor de desistir do sonho de retornar à terra natal. $O$ Japão estava destruído econômica e moralmente. Já não havia mais orgulho que sustentasse um retorno. A primeira geração (os issei) havia deixado o Japão quando as reformas do período Meiji (1868-1912) propagavam nacionalismo e militarismo extremados. Os imigrantes haviam aprendido a acreditar na superioridade de sua raça $e$ cultura. A derrota se configurava como um duro golpe nessa crença. Afora isso, colocaram-se numa situação de isolamento, recusando-se a aprender a falar português e a se misturar aos brasileiros, na vã esperança de retorno. Logo perceberam que lhes restava apenas se voltar para a nova pátria e tentar seguir os passos que os nissei $e$ sansei (segunda e terceira gerações) já estavam trilhando: a assimilação cultural. O resultado de uma pesquisa feita por Saito e Izumi em 1957 foi taxativo: "mais de 85\% dos adultos entrevistados declararam que seu plano para o futuro era permanecer definitivamente no Brasil" (Saito, 1973: 461).

Se internamente a colônia japonesa necessitava urgentemente unir-se e resgatar sua auto-estima destruída na guerra, buscando uma identidade enquanto grupo, externamente, em relação aos brasileiros, precisava apagar a imagem de grupo inassimilável, que assustava com seu exarcerbado nacionalismo (Comissão de Elaboração, 1992: 398, 399). "A década de 50 é um marco na busca de novos caminhos pelos imigrantes e seus descendentes" (Sakurai, 1993: 16).

Entretanto, nesta mesma década o Brasil também ilecessitava mudar sua imagem. A tão propalada "vocação agrária nacional" não fazia mais sentido frente ao grande processo de industrialização e urbanização pelo qual passava o país depois da Segunda Guerra Mundial. Mesmo o poder político já fugia das mãos da aristocracia rural para cair nas mãos da burguesia industrial. São Paulo, com uma população de 2.817 .600 habitantes em 1954, despontava como a maior metrópole brasileira, ultrapassando a capital federal (Meyer, 1991: 4-53). Transformada no maior pólo industrial do país, constituiu-se na porta de entrada do capital e da tecnologia estrangeira. Culturalmente também a metrópole paulista procurava internacionalizar-se: no fim dos anos 40 e começo dos anos 50 várias instituições típicas da cultura de massas surgem no cenário paulistano. Num esforço para fazer cinema que pudesse competir em qualidade com o mercado internacional, é fundada a Companhia Vera Cruz que, para esta finalidade, importou técnicos estrangeiros. O Teatro Brasileiro de Comédia, fundado em 1948, também navegava nas mesmas águas da Vera Cruz: trazer ao Brasil a cena internacional, utilizando, para isto, os técnicos, diretores e atores estrangeiros que já se encontravam no país. No campo das artes plásticas a cidade assistiu, em 1947, à fundação do MASP (Museu de Arte de São Paulo) por Assis Chateaubriand, e no ano seguinte à fundação do MAM (Museu de Arte Moderna) pelo empresário Francisco Matarazzo Sobrinho. Como desenvolvimento deste processo de internacionalização da cultura brasileira foi 
organizada, em 1951, a primeira Bienal Internacional de Artes Plásticas de São Paulo. No ano anterior já havia sido inaugurada a primeira rede de TV brasileira, a TV Tupi, abrindo-se com ela uma porta para que a cultura de massas se consolidasse definitivamente no país (Pinto, 1993: 62).

Colaborava ainda para a imagem cosmopolita da cidade de São Paulo a diversidade de seus imigrantes. Segundo o Censo de 1950, havia um total de 276.815 habitantes japoneses no estado de São Paulo, sem contar os imigrantes europeus que eram maioria (Cardoso, 1973: 317). A presença destes imigrantes teve um papel positivo para a penetração da produção industrial, cultural e artística internacionais.

A nova cultura cosmopolita, a indústria cultural e o desenvolvimento industrial uniram-se para fazer de São Paulo a ponta de lança de um projeto nacional desenvolvimentista que tomou um perfil definitivo em 1956, com o Plano de Metas de Juscelino Kubitschek.

Logo, nada mais natural do que utilizar o IV Centenário da emergente metrópole como evento ideal para que se propagasse esta nova imagem, dentro e fora do país. Com isto em mente os governos municipal e estadual convidaram várias comunidades de imigrantes para participarem das comemorações. Elas deveriam criar marcos, que atestassem sua presença na cidade, a serem inaugurados nas festas do IV Centenário (Comissão de Elaboração, 1992: 396, 397).

Em 1952, a convite do então prefeito da cidade, Armando Arruda Pereira, formouse a Comissão Colaboradora da Colônia Japonesa Pró-Centenário da Cidade de São Paulo. Foi decidido que seria construído um Pavilhão Japonês, inspirado no Palácio Katsura, de Quioto, no terreno do que viria a ser o Parque do Ibirapuera (Comissão de Elaboração, 1992: 398).

Para o mundo do chá, o IV Centenário foi também um momento determinante. No Pavilhão Japonês aconteceram as primeiras apresentações de chanoyu no Brasil como parte destas comemorações. Para isso veio ao país Sen Soshitsu, na época o primeiro na linha sucessória de grão-mestres do estilo de chá Urasenke.

Uma presença tão importante deveu-se ao fato de que, também para o governo japonês, era necessário tentar mudar a imagem belicosa que o Japão havia adquirido com a guerra. Nas décadas de 50 e 60, a escola de chá Urasenke, com apoio do governo japonês, não mediu esforços para ajudar o mundo a esquecer o Japão Kamikaze. Inaugurou centros de chanoyu no Brasil, Argentina, Peru, México e nos Estados Unidos, e divulgou um outro lado da cultura japonesa, o lado espiritual e filosófico (Mori, 1988: 218).

As demonstrações de inauguração ocorreram entre os dias 2 e 16 de outubro de 1954. Os imigrantes compareceram em peso. Na época em que haviam saído do Japão, o chanoyu era uma arte essencialmente da elite masculina, e poucos eram os imigrantes que tinham podido aprendê-la (entrevistas com praticantes). Se no Japão, durante e depois da Segunda Guerra, ela havia se democratizado e se disseminado entre as mulheres e a classe média em geral (Mori, 1988: 15,16) poucos foram os imigrantes que haviam presenciado este processo. A grande maioria ainda julgava o chanoyu distante de suas possibilidades.

Logo que chegou, no dia 2 de outubro de 1954, Sen Soshitsu participou de uma cerimônia oficial no Pavilhão com a presença do cônsul-geral do Japão, Chiba. Nesta 
ocasião doou todos os utensílios de chá e alguns kimonos que havia trazido para as demonstrações. Nos dias que se seguiram fez palestras e demonstrações nas casas de pessoas importantes da colônia, culminando numa grande aula aberta no dia 13 no mesmo pavilhão. Três dias depois foi fundado o shibu, ou sucursal brasileira da escola de chá Urasenke, no antigo hotel Niterói, no bairro da Liberdade, em São Paulo (Tankosha Newsletter, dez. 1954). Começa aí a história institucional do chanoyu entre nós.

\section{O que Procuraram os Japoneses que Foram Estudar o Chanoyu?}

Tomoo Handa, imigrante japonês que se tornou pintor no Brasil, é o autor de um artigo sobre a perda do senso estético em meio aos imigrantes japoneses no Brasil. Handa identifica a causa desta perda no fato dos imigrantes japoneses terem vindo ao Brasil em caráter temporário, com o intuito de voltar ao Japão logo que conseguissem dinheiro suficiente. Tendo em mente somente o trabalho, não se permitiam tempo livre para tentar fazer a vida no Brasil mais aprazível. Não trouxeram instrumentos musicais ou outros objetos artísticos, e também quase não comemoravam suas festas típicas, ou rituais religiosos. Se não estavam trabalhando na roça, estavam trabalhando na horta particular ou em casa. O que tornava mais crítica esta situação era o fato de que "[...] o senso estético do Japão [...] constitui a tradição viva cotidiana [...], não pode ser dissociado da vida (e o) centro da existência (está baseado no) tatami" (Handa 1973: 393). O que o autor alega é que as casas de colono, onde foram morar os primeiros imigrantes, eram em tudo diferentes do que estavam acostumados. O chão de terra batida (ao invés de madeira ou tatami), as camas para dormir (ao invés de futon), as paredes de pau a pique (ao invés do fussuma ou do shoji, de papel e madeira), juntamente com a total falta de tempo para o lazer, não ofereciam qualquer possibilidade de cultivar a vida cotidiana japonesa. Com a perda desta, perdeu-se também o senso estético japonês.

Handa lamenta a perda do modus vivendi do Japão tradicional como uma perda pessoal - ao longo do texto o autor sempre usa a primeira pessoa do plural, nós, para tratar dos sentimentos dos japoneses. "Os imigrantes [...] (que) viajam ao Japão [...] têm a emoção ao rever o que se perdeu em nós. O quanto nossa vida se tornou ríspida, com perda de finura" (Handa, 1973:410). Sente que os imigrantes perderam este senso artístico e não souberam olhar para seus pares brasileiros para com eles aprender um novo senso artístico, que seria mais adaptado à nova terra. Instalou-se portanto um vazio que, de acordo com ele, só pôde ser preenchido quando os nissei (segunda geração) trouxeram para o seio da comunidade japonesa a maneira brasileira de ordenar artisticamente a vida.

O testemunho de Handa, desejando a retomada da sensibilidade japonesa, funciona como um paradigma dos sentimentos dos issei em relação à esta perda. Com certeza, quando a oportunidade apareceu, foi isto que foram procurar com sofreguidão no aprendizado do chanoyu e de outras artes tradicionais: esta finura e delicadeza da sensibilidade perdida. 


\section{Porque Havia Poucos Nissei Interessados em Aprender o Chanoyu nas Décadas de 50 e 60 ?}

Se a meta principal das famílias de imigrantes de antes da guerra era fazer dinheiro rápido para voltar ao Japão, o que acarretava o isolamento da comunidade brasileira, com a derrota do Japão os planos tiveram que ser mudados. A permanência no Brasil tornou-se um fato inelutável. No pós-guerra os imigrantes issei tinham como nova meta o êxito econômico e a ascensão social de seus filhos. Compreendiam que as condições básicas para que isto acontecesse eram que falassem bem a língua portuguesa e se comportassem, em certa medida, como brasileiros.

Para os pais, desde a maioridade dos filhos, se torna preocupação que pelo menos um deles ingresse na faculdade. [...] Na sociedade brasileira, a consciência de que o trabalho manual não é digno da classe média é bastante acentuada. (Maeyama, 1967: 174)

Entretanto, os pais não poderiam funcionar como modelo de comportamento para seus filhos, mas tão-somente incentivar sua adaptação. Este vácuo na educação foi preenchido pelas centenas de associações de descendentes japoneses que forneciamlhes o ambiente ideal para que discutissem seus problemas comuns e convivessem com jovens em igual situação. Para os descendentes, que saíam do campo e chegavam à cidade com o intuito de estudar, elas funcionavam como uma ponte entre seu background rural e japonês e a sociedade brasileira que deveriam enfrentar. Nas associações eles discutiam temas como o namoro, e o casamento ${ }^{3}$, planejavam atividades esportivas e excursões, e ensinavam a dançar à maneira ocidental.

As associações têm uma função específica: abrasileirar onissei, fornecendo-lhe pelo menos padrões de comportamento adequados. [...] dão-lhe um núcleo de convivência em que se usa apenas a língua portuguesa, cujo domínio é condição importante para o sucesso nos cursos escolares e vida profissional. (Cardoso, 1973: 331)

Por consequiência, os nissei começaram a desejar a ocidentalização, identificando os padrões de comportamento brasileiro aos padrões da classe alta, a qual pretendiam ascender. Os costumes dos pais são identificados como antigos, de classe baixa, obstáculo para o seu sucesso.

Esta estreita identificação entre, por um lado, os valores da sociedade branca brasileira com os de uma classe social à qual se aspira e, por outro, dos valores da comunidade de origem com os de uma classe a que se renega, foi estudada por Roberto Cardoso de Oliveira, quando investigou o relacionamento entre índios e brancos no Brasil. Cunhando o termo "fricção interétnica", o autor vê a existência de modelos de sistemas interétnicos de simetria (implicando relações igualitárias) e de assimetria

3. Na época que imigraram, a maioria dos casamentos era ananjado (Omiai). O amor romântico é uma idéia que veio junto com a ocidentalização, depois da Segunda Guerra Mundial, e mesmo hoje não faz parte integral da sociedade japonesa. 
(relações hierárquicas). No caso do relacionamento entre descendentes japoneses e a sociedade brasileira, a partir do que foi dito até este momento, creio que estamos lidando com o segundo tipo, o de relacionamento assimétrico, onde valoriza-se a cultura da sociedade global envolvente, em detrimento daquela de origem. Diz Roberto de Oliveira a este respeito:

(O termo) "fricção interétnica" [...] serve para enfatizar o caráter conflituoso* das relações interétnicas, moldadas por uma estrutura de sujeição-dominação. Tal estrutura é uma réplica no plano étnico (i.e., das relações interétnicas) da estrutura de classes no plano social global (i.e., da sociedade nacional inclusiva). (Oliveira, 1976: 55,56)

Dito isto é possível identificar as razões pelas quais poucos descendentes nissei e sansei se interessaram pelo aprendizado do chanoyu, que valorizava a cultura japonesa. $\mathrm{Na}$ década de 50, quando o chanoyu começou a ser ensinado no Brasil, os nissei estavam começando a trilhar este caminho em direção à cultura brasileira. Estavam se desgarrando de costumes tradicionais, procurando encontrar uma nova identidade que correspondesse à sua condição de estar a meio caminho entre a cultura dos pais e a de seus colegas de escola e trabalho. Não era o momento de despender esforços para aprenderem a ser integralmente japoneses. Ao contrário, era o momento de livrar-se destes entraves que impediam sua integração à sociedade brasileira. Isseis e nissei, partindo do campo, tomaram caminhos distintos: se os primeiros se apegaram aos valores japoneses, os últimos se esforçaram por aprender a ser mais brasileiros. Nos longos anos no meio rural, os issei haviam tentado desesperadamente preservar o "espírito japonês". cultivando a língua e certos costumes. Contudo, sabiam que haviam deixado muito para trás:

Todavia, não terá havido imigrante que tivesse abandonado os seus costumes mais do que o japonês. Desde o dia da chegada teve que morar numa casa sem tatami, tirar kimono, jogar fora a tigela e o hashi, beber café ao invés de chá. (Handa, 1973: 400)

Vindo morar na cidade de São Paulo ${ }^{4}$, e passando a ter uma situação econômica mais estável, este configurava-se como o momento ideal para que os issei aprendessem a comportar-se como imaginavam que a elite japonesa o fazia.

Pensando na tradição cultural que os imigrantes trouxeram consigo, Manuela Carneiro da Cunha nos ensina que "a tradição cultural serve [...] de 'porão', de reservatório onde se irão buscar, à medida das necessidades do novo meio, traços culturais isolados do todo, que servirão essencialmente como sinais diacríticos para uma identificação étnica" (Cunha, 1987: 88). Portanto, somente na década de 50 os imigrantes tiveram meios e possibilidades materiais de "importar" um traço cultural tão importante

* Grifo do autor

4. Este processo de urbanização da comunidade japonesa continua presente até nossos dias. O último censo da população japonesa residente no Brasil, realizado em 1988 pelo Centro de Estudos Nipo-Brasileiros, dava conta que havia uma população de 1.168 .000 indivíduos. Deste total, $70 \%$ (828.000) viviam no Estado de São Paulo. Mais ainda, 89.2\% (1.042.000) habitavam a zona urbana. (Guia da Cultura Japonesa em São Paulo, 1989: 25). 
para sua afirmação enquanto parte da comunidade japonesa, e para a conseqüente distinção dos outros grupos que faziam parte da sociedade brasileira. A este mesmo respeito diz ainda a autora: "[...] não se levam para a diáspora todos os seus pertences. Manda-se buscar o que é operativo para servir de contraste" (Cunha, 1987: 101).

Vale lembrar que o pequeno número de nissei e sansei encontrados nas aulas de chanoyu nas décadas de 60,70 e 80 correspondem àqueles que haviam freqüentado as aulas desde pequenos, trazidos por seus avós e pais. Entre eles está Megumi, neta de japoneses, cuja avó a levava às aulas todos os sábados:

Minha avó me levava para todo lado. O chá era como a continuação da casa. Programa de sábado era passar o dia todo lá, fazíamos temae (cerimônia) de manhã, almoçávamos tranquiilamente, ficávamos à tarde, ou fazíamos outro temae ou víamos o dos outros. Era muito gostoso.

Mesmo estes jovens, que junto com seus familiares praticavam o chanoyu, passam por um distanciamento quando começam a freqüentar a universidade e se tornam mais independentes. Neste momento os estudos e outras atividades fazem com que ochanoyu receba paulatinamente menos prioridade em suas vidas.

Pensando o chanoyu como espaço de socialização, de aprendizado de regras de comportamento e valores japoneses, percebe-se que a partir do momento que se tornam adultos, estas regras já devem estar internalizadas e eles podem afastar-se do mundo dos pais.

Neste sentido, nota Takashi Maeyama a propósito da seita Seicho-no-iê no Brasil:

Com o amadurecimento da personalidade e da autonomia, eles (os jovens que faziam parte da seita desde crianças*) se afastarão da Associação e dificilmente chegarão a participar de Shiŷ́-Kai (Associação dos Homens) ou Shirohato-kai (Associação das Senhoras). Surge, por conseguinte, a deslocação [sic] entre a camada de jovens e velhos, ampliando-se cada vez mais com o correr do tempo. (Maeyama, 1967: 279)

Ocorre o mesmo com Megumi e outros jovens entrevistados, antigos freqüentadores das aulas de chanoyu: apesar de lamentarem o não comparecimento às aulas, justificam sua ausência pela falta de tempo devido aos estudos e ao trabalho.

No fim dos anos 80 e começo dos anos 90 esta situação se transforma bastante. $O$ Japão adquire um papel de destaque na nova ordem mundial e sua cultura valoriza-se. Os meios de comunicação brasileiros começam a utilizar a imagem de japoneses na publicidade, onde eles recebem um tratamento menos estereotipado do que lhes havia sido atribuído até então. Com a abertura das importações na era Collor, também os produtos da indústria japonesa chegam ao país. A imensa comunidade japonesa vê seus restaurantes invadidos por brasileiros ávidos por aprender os meandros do paladar oriental. A cultura japonesa transforma-se em símbolo de refinamento. Ilustra este fato um pequeno lembrete que sai mensalmente na revista VIP/Exame contendo um "pensamento Zen para recortar e guardar", que supostamente auxiliaria os negócios e daria tranqüilidade ao executivo que leva uma vida muito estressante.

* Nota da autora. 
Se a identidade étnica é definida "[...] em termos de adscrição: assim, é índio quem se considera e é considerado índio" (Cunha, 1987: 101), temos que enquanto não interessava aos descendentes serem reconhecidos como tal, fizeram todo o possível para aprender a ser brasileiros, não se vendo como japoneses. Mas, quando torna-se uma vantagem pertencer ao grupo, aí sim vão procurar aprender os valores e comportamento do grupo, para realmente fazerem parte dele. Roberto Cardoso de Oliveira nos fala de uma "[...] surrendered identity, uma identidade latente que é apenas 'renunciada' como método e em atenção a uma práxis ditada pelas circunstâncias, mas que a qualquer momento pode ser atualizada, invocada" [...] (Oliveira, 1976: 12).

É devido à revalorização da cultura japonesa no Brasil que esta identidade latente tem sido invocada através da procura de artes tradicionais, incluindo aí o chanoyu, por um número crescente de nissei e sansei. A eles se juntaram também os japoneses não imigrantes e brasileiros não descendentes.

\section{Conclusão}

Através deste pequeno artigo percebemos que o estudo do chanoyu e sua história podem ser utilizados como vias de acesso para entendermos o comportamento da população de imigrantes japoneses e seus descendentes no Brasil. Ao chegarem no Brasil instalaram-se no meio rural e, como não havia tempo suficiente para o lazer, o chanoyu não se apresentava como possibilidade de entretenimento. Entretanto, a vinda para a cidade, depois da Segunda Guerra Mundial, e a situação econômica mais estável fizeram com que, quando a oportunidade se apresentou, os imigrantes pudessem dedicarse ao estudo do chanoyu. Contudo, é importante perguntarmos que tipo de público interessou-se em praticá-lo. Não foram os nisseis, preocupados em aculturar-se para poder ascender socialmente, mas sim os isseis que, mais velhos, tinham tempo e poderiam dedicar-se a aprender o comportamento que acreditavam ser o apropriado da classe alta japonesa.

Com este artigo percebemos que, na década de 80, quando o Japão começou a ser valorizado como portador de uma cultura refinada e detentora de um lugar central na economia mundial, houve um novo interesse por parte dos nisseis e sanseis pela prática do chanoyu como via de compreensão de sua origem étnica. Deste modo, percebemos que o chanoyu não é simplesmente uma arte tradicional japonesa exótica aos olhos ocidentais, mas pode tornar-se uma boa ferramenta para se pensar sobre a visão de mundo, interesses e desejos dos imigrantes e descendentes de japoneses no Brasil.

\section{Bibliografia}

CARDOSO, Ruth (1973). "O Papel das Associações Juvenis na Aculturação dos Japoneses”. In Saito, H. e Maeyama, T. (org.). Assimilação e Integração dos Japoneses no Brasil, Petrópolis/São Paulo, Vozes/Edusp. 
COMISSÃo de Elaboração dos 80 Anos da Imigração Japonesa no Brasil (CEHIJB) (1992). Uma Epopéia Moderna - 80 anos da Imigração Japonesa no Brasil. São Paulo, Hucitec, Sociedade Brasileira de Cultura Japonesa.

CunHa, Manuela Carneiro (1987). Antropologia do Brasil. São Paulo, Brasiliense (2. ed.). Gula da Cultura Japonesa em São Paulo (1989). São Paulo, Aliança Cultural Brasil-Japão.

HANDA, Tomoo (1973). "Senso Estético na Vida dos Imigrantes Japoneses". In SAITO, H. e MAEYAMA, T. (org.). Assimilação e Integração dos Japoneses no Brasil, Petrópolis/São Paulo, Vozes/Edusp.

MAEYAMA, Takashi (1967). O Imigrante e a Religião - Estudo de uma Seita Religiosa Japonesa em São Paulo. Tese de doutoramento, FFCHL/USP.

MEYER, Regina M. P. (1991). Metrópole e Urbanismo-São Paulo Anos 50. Tese de doutoramento, FAU/USP.

MORI, Barbara Lynne (1988). Chado in Japan and Hawaii: A symbolic interactionist analysis of intra - and cross cultural transmition, adaptation and change. Tese de doutorado defendida na Universidade do Havaí publicada em facsímile pela Universidade de Michigan (UMI).

OliveIRA, Roberto Cardoso (1976). Identidade, Etnia e Estrutura Social. São Paulo, Biblioteca Pioneira de Ciências Sociais.

PinTo, Virgílio Noya (1993). Comunicação e Cultura Brasileira. Série Princípios, São Paulo, Ática.

SAITo, Hiroshi (1973). "Mobilidade e Assimilação de Imigrantes Japoneses" In SAITo, H. e MAEYAMA, T. (org.). Assimilação e Integração dos Japoneses no Brasil, Petrópolis/São Paulo, Vozes/Edusp.

SakuraI, Célia (1993). "A Fase Romântica da Política - Os Primeiros Deputados Nikkeis no Brasil”. In Imigração e Política em São Paulo, São Paulo, Sumaré/Fapesp.

TANKOSHA Newsletter (1954). Periódico publicado em japonês pela Fundação Urasenke, Kyoto. URASENKE Newsletter (1975-1998). Periódico publicado pela Fundação Urasenke, Kyoto. 